\title{
TRADUÇÃO E ENSINO DE LÍNGUA ESTRANGEIRA: UMA AGENDA DE PESQUISA DOS ANOS DE 2004 A 2013
}

\author{
Valdecy Oliveira Pontes* \\ Universidade Federal do Ceará
}

\author{
Bill Bob Adonis Arinos Lima e Sousa** \\ Universidade Federal do Ceará
}

Rafael Ferreira da Silva***

Universidade Federal do Ceará

\begin{abstract}
* Possui Licenciatura Plena em Letras Português / Espanhol pela Universidade Federal do Ceará (2006), especialização em Linguística Aplicada pela Faculdade Sete de Setembro (2009), mestrado em Linguística Aplicada pela Universidade Estadual do Ceará (2009), doutorado em Linguística pela Universidade Federal do Ceará (2012) e pós-doutorado em Estudos da Tradução pela Universidade Federal de Santa Catarina (2014). É Professor Adjunto, na graduação em Letras-Espanhol e no Programa de Pós-graduação em Estudos da Tradução (POET), da Universidade Federal do Ceará. Fortaleza, Ceará, Brasil. E-mail: valdecy.pontes@ufc.br

** Possui Licenciatura Plena em Inglês e Português pela Universidade Estadual Vale do Acaraú (2004), Especialização em Gestão e Coordenação Escolar (2013) pela mesma universidade e Especialização em Estudos de Tradução pela Universidade Federal do Ceará (2013). Atualmente é professor titular de língua inglesa - EEEP Professor Onélio Porto (SEDUC-CE) e Professor Colaborador das disciplinas de língua inglesa da Universidade Estadual Vale do Acaraú e Universidade Federal do Ceará (Instituto UFC Virtual). Fortaleza, Ceará, Brasil. E-mail: bill_sousa@hotmail.com

*** Graduado em Letras (Português - Literaturas 1998 e Português - Italiano 1999) pela UFRJ. Mestre (2002) e Doutor (2008) em Letras Neolatinas pela UFRJ. Professor membro da POET (Programa de Pós-graduação em Estudos da Tradução/ UFC). Professor Adjunto III de Língua, Literatura e Cultura Italiana na Universidade Federal do Ceará. Fortaleza, Ceará, Brasil. E-mail: rafarjbr@gmail.com
\end{abstract}


Resumo: Este artigo descreve e discute uma agenda de pesquisa em "tradução e ensino de língua estrangeira (LE)" que contempla os anos de 2004 a 2013. Investigam-se oito periódicos que versam sobre tradução, linguística e linguística aplicada; foram encontrados e coletados 20 trabalhos que se vinculam à temática aqui discutida. Objetiva-se, a partir desse trabalho, esboçar um quadro que possa representar a situação em que se encontram os estudos nessa área. Os dados colhidos nesse estudo mostram que há uma grande fragmentação das pesquisas em tradução e ensino de LE, pois verificou-se falta de sistematização desses estudos, bem como um volume pequeno em publicações considerando-se o espaço de tempo investigado.

Palavras-chave: Tradução. Ensino. Língua Estrangeira.

\title{
TRANSLATION AND FOREIGN LANGUAGE TEACHING: A RESEARCH AGENDA FROM THE YEAR OF 2004 TO 2013
}

\begin{abstract}
This paper describes and discusses a research agenda about "translation and foreign language (FL) teaching" which comprehends the year 2004 until 2013. Eight periodicals which publish about translation, linguistics and applied linguistics have been investigated; 20 works which are linked to the thematic discussed here have been found. The aim of this work is to outline a frame which may represent the current situation of the studies in this area. The data collected in this study show that there is a great research fragmentation concerning translation and FL teaching, since a lack of systematization regarding those studies has been verified, as well as a little amount of publication, considering the time length investigated. Keywords: Translation. Teaching. Foreign Language.
\end{abstract}

\section{Introdução}

Este trabalho se propõe a descrever e discutir a agenda de pesquisa em tradução e ensino de língua estrangeira (LE) dos últimos dez anos a contar de 2004, tomando como amostra artigos de oito revistas conceituadas que versam sobre os Estudos da Tradução, a Linguística e a Linguística Aplicada. Sendo uma área de conhecimento interdisciplinar, os Estudos da Tradução dialoga com várias áreas do conhecimento, contemplando a Linguística e a Linguística Aplicada, o que justifica a inserção das últimas nessa agenda. 
Com isso, pretende-se esboçar um quadro que possa representar a situação atual das pesquisas nesse tema e, assim, contribuir para a orientação ou reorientação desses estudos.

As pesquisas apresentadas aqui compreendem o período de 2004 a 2013, 10 anos. A opção por não incluir o ano de 2014 é devido ao fato de que essa agenda foi investigada no decorrer desse ano, não se tendo acesso, assim, a todas as publicações referentes a esse período. As pesquisas, corpus deste trabalho, versam sobre temas variados relacionados à utilização da tradução no ensino de língua estrangeira (doravante LE) ${ }^{1}$. Os dados colhidos nesse estudo mostram que há uma grande fragmentação das pesquisas em tradução e ensino de LE.

O corpo do trabalho está disposto em três seções. Na seção 2, faz-se a descrição do corpus e explicam-se os critérios de coleta usados na composição deste. Na seção 3, descrevem-se, resumidamente, as pesquisas desta agenda e discutem-se, de forma sucinta, suas contribuições para a Tradução e Ensino de Línguas, subárea dos Estudos da Tradução. E, na seção 4, destacam-se os pontos de convergência entre as pesquisas e ressaltam-se algumas contribuições advindas destas.

\section{Descrição do corpus}

O corpus dessa pesquisa é a reunião de artigos, disponíveis em formato eletrônico na internet, sobre tradução e ensino de LE, publicados em algumas das principais revistas ${ }^{2}$ do país que tratam das disciplinas dos Estudos da Tradução, da Linguística e da Linguística Aplicada, no intervalo de 10 anos, a contar do ano de 2004.

Foram investigadas as revistas: TradTerm, Cadernos de Tradução, In-Traduções, Traduzires, Horizontes de Linguística Aplicada, Abralin, Revista Brasileira de Linguística Aplicada e a revista Signum. As revistas escolhidas, inicialmente, são aquelas que representam os Programas de Pós-Graduação em Estudos da Tradução do país. As demais pelos critérios de antiguidade, disponibi- 
lidade de suas edições online e/ou representação, como a Revista Abralin da Associação Brasileira de Linguística. Foram coletados artigos escritos em português e inglês sobre tradução e ensino de LE, respeitando o intervalo de tempo que compreende os anos de 2004 a 2013. Ao todo, compõe o corpus desta pesquisa, das 121 edições investigadas, o total de 20 artigos.

O critério para coleta dos trabalhos é baseado na ocorrência das palavras-chave "tradução", "sala de aula", "ensino", "aprendizagem", "língua materna" e "língua estrangeira" (e/ou "inglês", "espanhol", "francês", "português", etc.) em pares ou em combinações que sugerem o tema do trabalho no título do artigo e que possa vinculá-lo, dessa forma, a essa agenda. Essa ocorrência foi verificada através da leitura dos títulos constantes nos sumários de cada revista, de cada edição, que ficam hospedadas no site destas. O mecanismo de busca do site das revistas não foi utilizado. Seguem os dados obtidos através da coleta do corpus em cada revista.

As revistas que tratam especificamente sobre tradução somam quatro. A revista TradTerm, Qualis-CAPES B1, do Centro Interdepartamental de Tradução e Terminologia da USP, publicou, no período destacado, um volume/ano, com exceção dos anos de 2010 e 2012, nos quais constam dois volumes em cada, totalizando-se 14 edições que foram investigadas. A revista traz dois artigos sobre tradução e ensino de LE em edição de 2004 e um em edição de 2011, perfazendo três trabalhos coletados. A revista Cadernos de Tradução, Qualis-CAPES A1, da Pós-Graduação em Estudos da Tradução da UFSC, publica dois volumes/ano, totalizando, assim, 20 edições investigadas aqui. Nessa revista, em edição de 2011, encontramos publicações sobre o tema em questão numa seção da revista intitulada "Dossiê de Tradução e Ensino de Língua Estrangeira", com quatro publicações, três escritas em português e uma escrita em inglês. Total de quatro trabalhos coletados.

A revista In-Traduções, Qualis-CAPES B3, do Programa de Pós-Graduação em Estudos da Tradução da UFSC, hospeda em seu site somente as edições a partir do ano de 2009, sendo: um volume em 2009, dois em cada ano de 2010, 2011 e 2012, e três no ano de 
2013. Total de 10 volumes. Identificamos trabalhos sobre o assunto em estudo, num total de três, em edição de 2011, numa seção intitulada "Dossiê". A revista Traduzires, Qualis-CAPES B3, do Programa de Pós-graduação em Estudos da Tradução da UnB, conta com quatro edições, dois volumes publicados em 2012 e mais dois em 2013. Encontramos um trabalho em edição do ano de 2012.

As outras quatro revistas, que são descritas a seguir, publicam trabalhos no âmbito da linguística e da linguística aplicada. A revista Horizontes de Linguística Aplicada, Qualis-CAPES B1, da Pós-Graduação em Linguística Aplicada da UnB, hospeda em sua página na web edições a partir do ano de 2008 que totalizam 11 edições, pois para o ano de 2013 consta somente um volume. Os trabalhos publicados sobre tradução e ensino são do ano de 2009 e totalizam oito. A revista Abralin, Qualis-CAPES A1, da Associação Brasileira de Linguística, hospeda em seu site os volumes da revista que datam a partir de 2007. Sendo um volume em 2007 e dois em cada ano subsequente, com exceção de 2011 em que encontramos três volumes e 2012 quando temos apenas um. Somando 13 edições. Não foram encontrados trabalhos sobre tradução e ensino de LE.

A Revista Brasileira de Linguística Aplicada, Qualis-CAPES A1, do Programa de Pós-Graduação em Estudos linguísticos da UFMG, publicou até o ano de 2009 duas edições/ano, e, a partir de 2010, publica quatro adições/ano. Desse modo, a amostra aqui examinada perfaz 28 edições. O único artigo coletado data de 2006. As demais edições não registram trabalhos que atendam a essa pesquisa. A revista Signum, Qualis-CAPES A2, do Programa de Pós-Graduação em Estudos da Linguagem da UEL, publica dois volumes/ano, com exceção do ano de 2012 no qual foram publicados três volumes, totalizando 21 edições no intervalo de tempo em análise. Não foram encontrados trabalhos sobre tradução e ensino de LE.

Os dados do corpus selecionado nessa agenda de pesquisa podem ser observados no quadro 1. 


\begin{tabular}{|l|l|l|}
\hline REVISTAS & EDIÇÕES & ARTIGOS \\
\hline TRADTERM & 14 & 03 \\
\hline CADERNOS DE TRADUÇÃO & 20 & 04 \\
\hline IN-TRADUÇÕES & 10 & 03 \\
\hline TRADUZIRES & 04 & 01 \\
\hline $\begin{array}{l}\text { HORIZONTES DE LINGUÍSTICA } \\
\text { APLICADA }\end{array}$ & 11 & 08 \\
\hline ABRALIN & 13 & 00 \\
\hline $\begin{array}{l}\text { REVISTA BRASILEIRA DE } \\
\text { LINGUÍSTICA APLICADA }\end{array}$ & 28 & 01 \\
\hline SIGNUM & 21 & 00 \\
\hline TOTAL & $\mathbf{1 2 1}$ & $\mathbf{2 0}$ \\
\hline $\mathbf{0 8}$ & \multicolumn{2}{|l}{} \\
\hline
\end{tabular}

Quadro 1: Dados do corpus da agenda de pesquisa

Seguem-se a descrição e discussão do corpus dessa pesquisa, 20 artigos científicos, em ordem cronológica. Optou-se por essa sequência par que pudéssemos avaliar o volume de produção de cada período, assim como os temas contemplados. Não se pretende ser exaustivo na descrição dos trabalhos dessa agenda, antes se busca de forma objetiva caracterizar as pesquisas e destacar seus pontos fortes.

\section{Pesquisas em Tradução e Ensino de LE}

Os artigos descritos e discutidos nessa pesquisa compõem o que chamamos, aqui, de agenda de pesquisa em tradução e ensino de LE dos anos de 2004 a 2013. Nos anos de 2005, 2007, 2008, 2010 e 2013 não foram encontrados trabalhos publicados que satisfizessem aos critérios de busca desta pesquisa. A vinculação de cada pesquisa a essa agenda também é discutida a partir da sua 
contribuição para o desenvolvimento de estudos que contemplem a inserção da tradução no ensino de LE. Esse trabalho, embora um recorte em termos de tempo e periódicos, configura-se como um testemunho inteligível e crítico do panorama atual do desenvolvimento dos estudos nessa área. Torna-se, assim, um instrumento útil à condução de uma nova agenda para os anos que se seguem. Passamos a examiná-lo.

\subsection{4}

No ano de 2004, publicaram-se dois artigos sobre tradução e ensino de LE, ambos na área da Linguística de Corpus.

$\mathrm{O}$ primeiro artigo examinado aqui intitulado Um corpus multilíngue para ensino e tradução - o COMET: da construção à exploração (2004) de Stella E. O. Tagnin, publicado na revista TradTerm, destaca os corpora em construção em âmbito nacional como o COMPARA e o CORDIALL, mostrando que essa área dos estudos linguísticos vem ascendendo nos últimos anos. Uma das razões dessa ascensão é sua contribuição para o "conhecimento das línguas estudadas, em diversos âmbitos" (TAGNIN, 2004, p. 121). A autora toma como exemplo, nesse caso, a abordagem DDL (Data Driven Learning) ou aprendizagem por meio de dados, que permite que o aluno aprenda "por descoberta". Tagnin (2004) prossegue seu trabalho apresentando, justificando e descrevendo o COMET:

Face à enorme possibilidade de pesquisas contrastivas no âmbito do ensino de línguas estrangeiras e da tradução e, principalmente, ao fato de não haver corpora bilíngües de áreas técnicas que envolvam o português brasileiro, decidiuse pela construção do COMET - um Corpus Multilíngüe para Ensino e Tradução (TAGNIN, 2004, p. 123). 
O COMET é constituído de três subcorpora: um Corpus Técnico-Científico, um Corpus de Aprendizes e um de Traduções (TAGNIN, 2004, p. 123).

Tagnin (2004) explica que a construção de um corpus, para que atenda a objetivos específicos, deve observar rigorosos critérios de compilação. A autora demonstra, nesse sentido, que entre outros cuidados é essencial: delimitar a área que o corpus abrange, verificar a qualidade linguística dos textos e a idoneidade das fontes, fazer o tratamento dos textos (retirando elementos extratextuais, por exemplo), observar os direitos autorais, inserir os textos na íntegra. E conclui seu trabalho diferenciando os tipos de corpora que o COMET comporta, quais sejam: corpora comparáveis, corpora paralelos e corpus de tradução.

Esse tipo estudo ajuda a preencher uma lacuna nos estudos linguísticos sobre tradução e ensino de LE, à medida que reúne textos de várias línguas, sejam originais ou traduções, mostrando suas peculiaridades constitutivas, e, ao passo que, a partir do estudo contrastivo pode-se perceber que o processo de escrita de um texto em dada língua difere em aspectos linguísticos e culturais de outro texto em outra língua e cultura.

No segundo artigo, intitulado Translation corpora in contrastive research, translation and language learning (2004) de Josef Schmied, publicado na revista TradTerm, destaca-se sua definição de corpus como

uma coleção de textos que são a base para análises linguísticas e, em termos mais restritos, atualmente, como uma representação abrangente passível de leituras computadorizadas (material em formato eletrônico, por exemplo) ${ }^{3}$ (SCHMIED, 2004, p. 84, tradução nossa).

Os corpora, no estudo de Schmied (2004), assumem diversos usos para o ensino de LE. Um deles é uma ferramenta de apren- 
dizado de línguas chamada The Chemnitz Internet Grammar (com um corpus de tradução inglês-alemão) que permite aos usuários estudarem a gramática da língua inglesa de forma intuitiva e dedutiva, como também os monitora durante seu aprendizado fornecendo feedback (SCHMIED, 2004, p. 88). Outro uso é o DDL, supramencionado (TAGNIN 2004), que apresenta ao aprendiz exemplos de uso gerados automaticamente a partir de corpora de traduções, fazendo com que aquele perceba padrões naturais da língua e aprenda de forma intuitiva (SCHMIED, 2004, p. 103).

O trabalho de Schmied (2004) é instigante porque propõe usos práticos dos corpora de tradução e das TI para o ensino de línguas, possibilitando ao aprendiz novos meios de usar a tecnologia ao seu favor. Esse estudo fomenta pesquisas que visem a desenvolver softwares baseados em corpus de tradução para o aprendizado de LE.

\subsection{6}

No ano de 2006, publicou-se um artigo sobre tradução e ensino de LE. O artigo intitulado Leitura, literatura e tradução: a necessidade de adequações no ensino de línguas não-maternas (2006), de Sergio Flores Pedroso, publicado na Revista Brasileira de Linguística Aplicada, equaciona o uso da literatura, da língua materna (LM) e da tradução como elementos relevantes, quando bem explorados, ao ensino de LE. O autor assevera que a LM

não é instrumento, é o lugar inaugural do saber e através dela se reorganizam e adaptam os saberes em outras línguas, numa base em que o componente sócio-histórico é o fundamento do caráter relacional que constitui a abordagem de toda $L E^{4}$ (PEDROSO, 2006, p. 12).

Nesse sentido, critica a "demonização" ao uso da LM no ensino de LE, argumentando que os que a rejeitam acreditam que 
podem reproduzir num processo "irrepetível: o processo de inscrição do sujeito na língua materna" (PEDROSO, 2006, p. 14). Critica também o uso limitado da tradução em livros didáticos de LE, sublinhando algumas práticas como o trabalho com listas de palavras, orações soltas, expressões idiomáticas ou formulaicas e com orações num tempo verbal determinado. E propõe atividades que "cumpririam o objetivo de conseguir enunciação e sensibilização ao discurso a partir do trabalho com o argumentativo, com o formulativo e com a conjunção de ambos" através da literatura (PEDROSO, 2006, p. 21). Como as que observam-se a seguir, referentes a Confieso que he vivido, de Pablo Neruda:

1) Explica qué no le gusta de Santiago a la pareja.

2) ¿Cómo el poeta se refiere a las flores y al crecimiento de plantas en invierno?

3) Di eso a tu manera en español.

4) Traduce al portugués las palabras del escritor.

5) Escribe eso en portugués corriente.

6) Refiérete con tus palabras en español y resumidamente a lo que dice el párrafo.

7) Esta es una traducción al portugués de ese libro. Lee la traducción de las oraciones que hiciste y la comercial. Vamos a discutir las diferencias.

8) Trata de narrar en español en el papel lo mismo que cuenta el escritor, pero de forma sencilla. Préstales atención a las diferencias (PEDROSO, 2006, p. 22).

A pesquisa de Pedroso (2006) contribui à prática do ensino de LE através da tradução quando discute o caráter sócio-histórico-ideológico das línguas naturais e quando propõe um papel ativo e crítico ao estudo de LE em sala de aula. 


\subsection{9}

No ano de 2009, publicaram-se oito artigos sobre tradução e ensino de LE, abordando temas variados. Apesar do aspecto fragmentário dessa agenda, tentamos dispor os estudos em paralelo, de forma que se ligassem numa relação de proximidade temática. Os quais são apresentados a seguir.

$\mathrm{O}$ artigo Translation and language learning: AlfraCovalt as a towol for raising learners' pragmalinguistic and sociopragmatic awareness of the speech act of requesting (2009), de Josep R. Guzman e Eva Alcón, publicado na revista Horizontes de Linguística Aplicada, questiona se e como a tradução pode ser aplicada no ensino LE para desenvolver a consciência pragmática do aprendiz no que tange ao ato de "pedir". Guzman e Alcón (2009) consideram que a tradução não é um procedimento linguístico, mas um ato de comunicação entre culturas. Na visão dos autores, usar a tradução na aula de LE pode ser o primeiro para passo para elevar a consciência sócio-pragmática e linguístico-pragmática dos alunos. Nesse estudo, ainda, é testado o Alfracovalt, um programa que processa corpora de traduções, dentre eles, um corpus com legendas de séries de TV.

A relevância de um estudo desse tipo está na naturalização da linguagem do aluno de LE, promovendo uma percepção da língua em uso que o leva a adequar sua construção discursiva à situação contextual mais imediata, tendo sempre em mente todo um contexto sócio-histórico mais amplo (BAKHTIN 2006) que definem as regras de enunciação em comunidades de fala específicas.

$\mathrm{O}$ artigo intitulado "Quem arrancou essa planta do meu jardim? Argumentos a favor do uso de legendas interlinguais no ensino de língua estrangeira" de Helena Santiago Vigata e Lúcia Maria de Assunção Barbosa, publicado na revista Horizontes de Linguística Aplicada, sublinha que, apesar do movimento pela aceitação da tradução como recurso didático no ensino línguas, ainda há a carência de propostas metodológicas que favoreçam sua implementação em sala de aula (VIGATA; BARBOSA, 2009, p. 221). Esse estudo re- 
força a importância do caráter multisemiótico do texto audiovisual (AV) para a aquisição de LE através de legendas interlinguais. As autoras assinalam que através da tradução "os espectadores contam com mais vias de recuperação da informação e se beneficiam tanto dos elementos visuais quanto dos dois códigos verbais" (VIGATA; BARBOSA, 2009, p. 221). A proposta de investigar a tradução nesse trabalho parte de uma perspectiva pedagógica, e não profissional, assim Vigata e Barbosa (2009) optam pelo termo "tradução pedagógica" para conceituar o tipo de tradução usada pelos alunos num exercício de sala de aula de LE. Fica claro ao final deste artigo que um dos seus pontos centrais é "a desmistificação da tradução, em todas suas modalidades, como erva daninha do nosso frutífero jardim - a aula de língua estrangeira" (VIGATA; BARBOS, 2009, p. 235).

Com desenvolvimento célere das novas mídias (GAMBYER, 2006), abre-se espaço para um novo tipo de letramento e aqueles que se interessam pelo campo audiovisual se beneficiam do estudo de Vigata e Barbosa (2009) por seu aspecto empreendedor e pelas diversas características do texto AV que podem ser exploradas em sala de aula e que são bem organizadas e expostas aqui.

No trabalho $O$ processo de elaboração de um glossário bilíngue de colocações da área médica: contribuições para tradutores e professores de língua inglesa (2009) de Fernanda Goulart Ritti Dias, publicado na revista Horizontes de Linguística Aplicada, o processo de composição de um corpus bilíngue é descrito em suas etapas constitutivas e é enfatizada sua aplicabilidade na escrita de versões de trabalhos de diversas áreas para o inglês, como forma de expandir o alcance e o reconhecimento destes. Também é destacada aqui a vantagem da utilização de tal corpus para produção textual em língua inglesa através do reconhecimento de colocações.

O texto de Dias (2009) ao descrever, ainda que forma sucinta, o processo de composição de um corpus bilíngue favorece a inclusão da tradução no ensino de LE ao passo que estimula a compilação de materiais autênticos em pares de línguas como forma, também, de aquisição de LE. 
O trabalho intitulado $A$ tradução como atividade contrastiva $e$ de conscientização na aprendizagem de línguas próximas (2009) de María Carolina Calvo Capilla e Mark Ridd, publicado na revista Horizontes de Linguística Aplicada, retoma a discussão sobre o uso da LM no ensino de LEs, usando para tal a questão da interferência da LM quando as línguas em contato são muito semelhantes, caso do português e o espanhol. A LM é vista aqui como uma "fonte de hipóteses e modelo para a aquisição da LE" (CALVO CAPILLA; RIDD, 2009, p. 154). Calvo Capilla e Ridd (2009) sugerem o uso da tradução como atividade contrastiva e de conscientização através do estudo da tradução como processo e da tradução interpretativa como re-expressão do sentido. Os autores ainda afirmam que a tradução foi proscrita, ao mesmo tempo em que foi proscrito o MGT, do ensino de LE sem nenhuma base científica alegando-se que seu uso interfere na produção dos aprendizes.

Pelo que foi visto até aqui, parece estar claro que as condições atuais são favoráveis para inserção da tradução como uma ferramenta complementar ao ensino de LE, fazendo-se vitais estudos que discutam e proponham atividades envolvendo a tradução em contextos de sala de aula.

$\mathrm{O}$ artigo intitulado Crenças de alunos de um curso técnico sobre o papel da tradução no ensino instrumental de línguas de Patrícia Dias Reis Frisene, publicado na revista Horizontes de Linguística Aplicada, apresenta os resultados de uma pesquisa-ação em que a professora-pesquisadora utiliza a tradução direcionada à leitura de textos técnicos. Através de questionários, diários e anotações foram colhidas informações sobre as impressões que os alunos tiveram a partir dos exercícios envolvendo a tradução. Entre esses exercícios figuraram os conceitos clássicos de tradução cunhados por Jakobson e sua aplicação (na leitura de imagens, por exemplo); e uma prática com uso de um tradutor automático, conscientizando os alunos sobre as possíveis lacunas daquele. Ao traduzir, os alunos foram expostos à importância de se considerar a tipologia textual quando se trabalha com gêneros discursos, fatores como contexto de produção 
e recepção e à relação que se estabelece entre língua e ideologia (FRISENE, 2009, p. 44).

A perspectiva de ensino instrumental de línguas pelo viés da tradução extrapola quesito fundamental da disciplina: estudar uma língua para fins específicos, uma vez que lida com outras questões essenciais à construção e interpretação de textos, contribuindo, dessa forma, para uma formação cada vez mais global.

$\mathrm{O}$ artigo Teorias da tradução e o ensino de língua estrangeira (2009) de Sinara de Oliveira Branco, publicado na revista Horizontes de Linguística Aplicada, é um estudo incipiente, empírico-experimental, que, fundamentado nas estratégias de tradução propostas por Chesterman (1997), busca mapear os discursos de alunos do Curso de Letras-Inglês da UFCG, em suas propostas de tradução, a fim de reconhecer quais são as estratégias mais usuais utilizadas por estes. Segundo Branco (2009), com o uso de estratégias de tradução em sala de aula de LE, não se objetiva formar um tradutor profissional, antes se pretende mostrar que a tradução pode ser mais um instrumento na aquisição de uma LE. Para a autora, o uso da tradução em sala de aula é profícuo desde que a atividade proposta seja "bem preparada e com objetivos claros, tanto para o professor quanto para o aluno” (BRANCO, 2009, p. 190).

O trabalho de Branco (2009) alerta os profissionais que buscam uma integração entre tradução e ensino de LE, para que essa combinação seja feita de forma planejada e coerente com os propósitos de um curso. Aspecto importante, já que o "mal uso" da tradução em sala de aula de LE, pode contribuir para um retrocesso no estado atual dessa agenda.

$\mathrm{O}$ artigo $O$ uso da tradução no ensino-aprendizagem das línguas estrangeiras (2009) de Sergio Romanelli, publicado na revista Horizontes de Linguística Aplicada, assim como outros trabalhos comentados dessa agenda de pesquisa, faz um breve histórico mostrando como a tradução figurou, ou deixou de figurar, no ensino de LE. Romanelli (2009) sugere alguns dos benefícios que a tradução pode trazer a esse ensino como promover a autonomia, diminuir o filtro afetivo ${ }^{5}$ em sala e favorecer o desenvolvimento de uma maior 
competência pragmática, metalinguística e cultural. Ele ressalta, entretanto, que o que se faz em seu estudo não é uma apologia à tradução, é antes, uma justificativa ao seu uso em algumas situações específicas. $\mathrm{O}$ autor conclui esse trabalho com a proposição de algumas atividades práticas envolvendo tradução.

Parece consenso entre os pesquisadores dessa subárea dos Estudos de Tradução que o uso da tradução no ensino de LE é fundamental nos estágios iniciais, especialmente quando se trata do ensino de uma língua com grandes diferenças lexicais e gramaticais. Entretanto, algo que não pode ser perdido de vista é sempre como, onde, em que condições e com quem se utiliza determinada atividade, para que a adequação desta possa realmente justificar o seu uso, trazendo ganhos reais para os alunos.

No trabalho $O$ ensino de línguas estrangeiras no Brasil e a “compreensão do estrangeiro": o papel da tradução (2009), publicado na revista Horizontes de Linguística Aplicada, Ruth Bohunovsky chama a atenção para o fato de que nossos modelos de aprendizagem de línguas sempre foram muito orientados por modelos de outros países, em especial os dos países onde a língua-meta é falada. Para discutir essa questão Bohunovsky (2009) destaca como a tradução no ensino de línguas é entendida no Quadro Comum Europeu e como essa concepção refletiria no contexto brasileiro. A autora explica que no documento supracitado a tradução é classificada como uma atividade de mediação linguística, já que em países do continente europeu é muito comum a presença de uma terceira pessoa, em um diálogo, desempenhando a função de intérprete; ainda, algumas vezes a tradução é excluída pelo caráter heterogêneo das turmas compostas de pessoas de nacionalidades diversas desencorajando o uso da LM. Uma transposição metodológica desse tipo ao nosso contexto não é muito promissora, segundo Bohunovsky (2009), pois, no Brasil, não se têm tantas oportunidades de usar a LE num contexto desse tipo e os alunos, massivamente, compartilham da mesma LM. A autora, então, sugere que a tradução, a despeito da orientação daquele documento, seja usada para "a comparação de versões diferentes de um mesmo 
texto de partida - tendo como objetivo principal a "aprendizagem crítico-reflexiva", concentrando-se em aspectos linguísticos e/ou culturais" (BOHUNOVSKY, 2009, p. 175).

A discussão instigante desse trabalho pode motivar pesquisas que proponham a reelaboração dos documentos que nos servem como orientação para o ensino de LE, como é o caso dos PCN e dos $\mathrm{OCN}^{6}$, por exemplo. Indo um pouco mais além, vislumbra-se até, o que constitui a opinião dos autores que investigam essa agenda, a formulação de um currículo mais inteligível e minimamente universal para o ensino de LE no ensino básico brasileiro, que peca por ser fragmentário e pouco prescritivo.

\subsection{1}

No ano de 2011, publicaram-se oito artigos sobre tradução e ensino de LE, abordando temas variados, os quais são apresentados abaixo.

No artigo, Translation as a teaching tool to bridge L1 and L2 for adult learners at elementary levels, publicado na revista Cadernos de Tradução, Natanael F. França Rocha chama a atenção para o fato da tradução ser uma ferramenta útil ao ensino de LE quando bem utilizada, e na situação inversa poder ser prejudicial. Rocha (2011a) ressalta que através da tradução os professores conseguem introduzir um novo vocabulário, explicar a gramática, comparar culturas, motivar os alunos, estimular a memorização, checar a compreensão do que está sendo ensinado e trabalhar com aspectos peculiares das línguas. Ao usar a tradução com alunos de um curso de inglês em nível inicial no desenvolvimento de habilidades orais e escritas, o autor concluiu, através de dados coletados dos informantes, que nenhum deles considera a tradução no ensino de LE como algo monótono e todos a consideram útil e prática (ROCHA, 2011a, p. 189).

A opinião dos alunos, no estudo de Rocha (2011a), se constitui como um dos principais dados, apesar do estudo apontar uma 
melhora no aprendizado destes, pois o fator motivação está relacionado, também, ao modo como o aprendiz recebe a abordagem de ensino-aprendizagem. Observamos que a tradução, em mais um caso analisado, é aplicada de forma a contribuir para o processo de ensino e aprendizagem de uma LE.

O estudo Tradução de frases: uma tentativa deliberada de fazer alunos deixarem de falar inglês em português! de Hanna Betina Götz, publicado na revista Cadernos de Tradução, busca evitar a fossilização dos discursos de aprendizes de língua inglesa no estágio de interlíngua de sistematização e estabilização. Buscou-se, nesse sentido, através da análise contrastiva de frases traduzidas que os alunos usassem a LE de forma mais idiomática. A autora aponta que, através da sistematização desses exercícios, os alunos melhoraram não só suas habilidades linguísticas escritas como também orais.

Um aspecto importante do trabalho de Götz (2011) é a preocupação em munir o aprendiz de LE com estratégias de estudo para que este possa saber o que e como estudar por conta própria, avançando, assim, em seus níveis de proficiência. A autora mostra que, nesse aspecto, a tradução pode prestar uma importante contribuição.

No trabalho $O$ papel da língua materna na sala de língua (2011), publicado na revista In-Traduções, Roberta Ferroni, a exemplo de muitos outros autores que compõem essa agenda, traça um histórico das principais abordagens utilizadas para o ensino de LE. O que destaca o estudo de Ferroni (2011) dos demais é o foco de sua investigação que trata da aceitação e da rejeição do uso da LM nesses métodos, explicando os possíveis fatores que possam ter motivado isso. A autora percebeu que o uso da LM sempre se deu numa relação binária, ou seja, ou de total exclusão ou de aceitação e que com o advento do método comunicativo a LM passa a figurar novamente no espaço do ensino de LE. Porém, ao passo que não proscreve a tradução, este método também não prescreve como fazer uso desta, ficando a cargo do professor decidir quando utilizá-la. Dessa forma, a autora reforça que “o próprio professor, 
dispondo de uma sólida formação teórica, poderá, conforme o contexto, elaborar sua própria abordagem, transformando-a em prática pedagógica" (FERRONI, 2011, p. 58).

A pesquisa de Ferroni (2011) é importante para essa agenda a partir do momento em que propõe o uso da LM, principalmente nos níveis iniciais, no ensino de LE como uma ferramenta de emancipação do aluno e do professor, que podem refletir sobre as melhores práticas de sala de aula, assim como sobre a melhor forma de estudar fora de sala. A tradução, nesse ensejo, figura como uma atividade a ser explorada através da literatura, dos produtos audiovisuais ou de qualquer recurso que se mostre promissor ao aprendizado de uma LE.

No trabalho As faces e funções da tradução em sala de aula de língua estrangeira, publicado na revista Cadernos de Tradução, Sinara de Oliveira Branco destaca as similaridades entre a abordagem comunicativa e a tradução funcionalista no ensino de LE. Baseada em Wills (1996) a autora entende que o desafio é a proposição de um "método que integre atividades que trabalhem a forma e a comunicação, fazendo com que a ideia de proximidade entre o Método Comunicativo e a Abordagem Funcionalista da Tradução fique mais evidente" (BRANCO, 2011, p. 166-167). Branco (2011) sugere atividades envolvendo tradução em sala de aula de LE de acordo com as categorias de tradução de Jakobson (2003) e utilizando a teoria funcionalista de tradução de Nord (1991), integrando aspectos linguísticos, culturais e textuais. A autora sinaliza alguns ganhos que podem provir desta abordagem como: expandir o vocabulário em LE, desenvolver o estilo dos alunos, melhorar o entendimento de como as línguas funcionam, consolidar as estruturas da LE, monitorar e melhorar a compreensão da LE (BRANCO, 2011, p. 169). Da forma semelhante à que outros autores fizeram em estudos investigados nessa agenda, Branco (2011) aponta o público adulto como um dos mais beneficiados pelo uso da tradução no ensino de LE, e também, o processo de substituição da tradução interlingual, usada nos níveis iniciais, pela tradução intralingual, usada nos níveis intermediários e avançados. 
O estudo de Branco (2011) é uma excelente defesa à inclusão da tradução ao ensino de LE através de atividades bem elaboradas e de um planejamento consistente. A teoria funcionalista de tradução e análise textual de Nord (1991), citada nesse estudo, suscita muitas possibilidades de uso da tradução em sala de aula, pois é uma teoria abrangente que contempla o exame de diversos gêneros textuais de uso potencial na prática pedagógica.

No artigo Tradução e ensino de línguas estrangeiras: confluências (2011), publicado na revista Cadernos de Tradução, Elisabetta Santoro argumenta a favor da tradução no ensino de LE fazendo inicialmente um apanhado histórico para mostrar, a exemplo de outros autores dessa agenda, como a tradução foi excluída dessa prática. Entre os vários benefícios que autora aponta, no que tange ao uso da tradução, destaca-se o aspecto que para traduzir o aluno deverá fazer uma leitura bem mais atenta e profunda, reconhecendo, assim, peculiaridades inerentes a cada língua tanto no campo linguístico como histórico-cultural. Santoro (2011) também discute a possibilidade da tradução ser considerada uma quinta habilidade em sala de aula. Nesse sentido, ela entende que as habilidades linguístico-comunicativas são diversas, extrapolando as quatro habilidades básicas e que por isso esta não parece ser "a formulação mais adequada" (SANTORO, 2011, p. 157), opinião da qual compartilhamos. Santoro (2011) ainda reconhece, a partir de muitos estudiosos, que vivemos na era do pós-método, em que há inclusão de abordagens e não exclusão. Com efeito, a simples indicação da tradução como uma leitura diferenciada já a licencia a ser incluída no rol das ferramentas utilizadas no ensino de LE que ganha em estratégias didáticas, tornando a sala de aula um ambiente mais aprazível.

No trabalho $O$ enriquecimento cultural através de atividades de tradução em aulas de língua estrangeira (2011), publicado na revista In-Traduções, Edelweiss Vitol Gysel entende que cultura são "os modos, hábitos e crenças e não só vai além do código, mas pode, através deste, demonstrar um cenário que reflete uma visão de mundo em certo contexto cultural" (GYSEL, 2011, p. 45). Partindo desse conceito, o autor julga imprescindível que haja o casamento entre 
língua e cultura no processo de tradução e esclarece que o uso da tradução em sala de aula de LE não visa a formar tradutores. Como já vimos em outros trabalhos dessa agenda, Gysel (2011) também faz opção por utilizar a expressão "tradução pedagógica" para se referir a um recurso didático e metodológico. Com esses pressupostos, o autor propõe atividades de tradução nos dois sentidos LE-LM e LMLE, que simulem situações de uso real, tanto de forma oral como escrita. Outro ponto que merece destaque nesse estudo, e que também está em consonância com outros estudos investigados nesse trabalho, é a indicação de redução do "filtro afetivo" através do trabalho com atividades de tradução em sala de aula.

A partir da proposição de atividades práticas que contemplem o que foi exposto acima, Gysel (2011) reforça o caráter positivo do uso da tradução no ensino de LE, seguindo na mesma linha dos demais autores que colocam a cultura com um aspecto de suma importância a ser trabalhado nesse processo de ensino e aprendizagem.

$\mathrm{O}$ trabalho de Natanael F. França Rocha, Tradução literal $e$ aprendizagem de línguas estrangeiras: uma estratégia para memorização (2011), publicado na revista In-Traduções, elenca vários estudos que sugerem que a tradução é uma boa estratégia para memorização lexical e sintática. Rocha (2011b) sugere o uso da tradução literal como uma forma de despertar no aluno a percepção das diferenças lexicais, sintáticas e idiomáticas de cada língua. Para isso, o autor recorre a atividades de tradução de palavras, expressões ou frases "soltas", mas com a aplicação de uma metodologia interessante. Por exemplo, no caso da tradução de frases, primeiro o aluno visualiza, numa tabela, a frase em LE, em seguida propõe-se uma tradução literal seguindo inclusive a ordem em que as palavras estão dispostas, e, por último na terceira coluna da tabela verifica-se "a forma equivalente na LM". A título ilustrativo, tomemos: "She is my age - Ela é minha idade - Ela tem minha idade” (ROCHA, 2011b, p. 90). Esse estudo mostra que mesmo a tradução literal, como uma fase intermediária de aprendizado, tem sua utilidade e que, assim, rechaçar esse recurso é perder em termos estratégicos no ensino de uma LE. 
O trabalho "A Grande Família - O Filme" $e$ "The Big Family The Film”: a tradução no ensino comunicativo de línguas (2011), de Marileide Dias Esqueda, Rosana Carla de Oliveira e Silvana Maria de Jesus, publicado na revista TradTerm, propõe uma atividade de tradução a partir de um filme legendado no sentido português-inglês tendo como informantes os alunos de um curso avançado em língua inglesa. Concentrando-se em algumas cenas que trazem expressões típicas do português brasileiro, o objetivo do exercício é traduzir esses diálogos para o inglês. As autoras destacam algumas das vantagens do uso do texto audiovisual numa atividade desse tipo, como a verificação ortográfica, o desenvolvimento da capacidade de leitura e de escrita e a otimização do uso de dicionários. Com base nessa atividade, as autoras chegaram à conclusão de que os informantes optaram por fazer traduções livres, estas não coincidindo entre si ou com a legenda da mídia (texto-fonte), a partir do que se inferiu que há diversas possibilidades de tradução para um mesmo texto, noção importante para aprendizes de LE.

$\mathrm{O}$ texto audiovisual é rico em significação. A combinação do texto verbal, oral e escrito, com a imagem torna essa mídia um recurso promissor para o trabalho em sala de aula de LE envolvendo atividades de tradução. Pode-se esperar, por exemplo, que os alunos expostos a esse tipo de texto utilizem a LE de forma mais idiomática.

\subsection{2}

No ano de 2012, publicou-se um artigo sobre tradução e ensino de LE o qual é apresentado abaixo.

$\mathrm{O}$ trabalho $A$ adaptação na sala de aula: relato da adaptação do conto "Kew Gardens", de Virginia Woolf, para o curta-metragem Intervalo e suas implicações na prática de tradução (2012) de Soraya Ferreira Alves, publicado na revista Traduzires, é o relato de uma atividade prática de tradução intersemiótica com alunos do curso de Letras da UECE. Para essa atividade Alves (2012) trabalhou com a adaptação do conto Kew Gardens de Vir- 
ginia Woolf para o cinema. Objetivou-se, com esse estudo, que os alunos, através do processo da produção de um texto audiovisual, a partir de um texto literário, percebessem as nuances que envolvem um processo de uma tradução desse tipo. A autora destaca, por exemplo, que houve um esforço para que muitos elementos do texto de partida fossem recuperados no texto de chegada, como as cores das flores descritas na obra literária, ressaltando o aspecto da compensação quando relata que na ausência de uma flor azul ao jardim do curta-metragem a câmera foi direcionada, ao focalizar o jardim, também ao azul do céu. Alves (2012) sublinha, ainda, as características significativas de um texto fílmico como os movimentos de câmera, os planos em que as personagens encontram-se, enquadramento, close-ups.

As perspectivas de se trabalhar com a relação entre textos literários e audiovisuais na tradução são inumeráveis. Essas atividades quando aplicadas em sala de aula de LE ou de tradução amplia a noção de texto dos alunos e os faz questionar elementos presentes nestes, com uma noção consistente que se tratam de escolhas deliberadas que seguem, também, via de regra, orientações político-ideológicas (cf. LEVEFERE 2007).

\section{A agenda dos anos de 2004-2013}

Pelo que se pôde observar, a agenda de pesquisa dos anos de 2004 a 2013, intervalo de 10 anos, não traz indícios que mostrem uma organização, um planejamento prévio feito por um grupo de pesquisadores no sentido de estabelecer metas. Viu-se, em contrapartida, que essa agenda está fragmentada, com pesquisas que versam sobre temas diversos e que se complementam apenas de forma tangencial. Vejamos, então, os principais pontos em que convergem. 


\begin{tabular}{|l|l|}
\hline $\begin{array}{l}\text { Pesquisas que sugerem o uso de } \\
\text { corpora de tradução no ensino } \\
\text { de LE }\end{array}$ & $\begin{array}{l}\text { Tagnin (2004); Schmied (2004); } \\
\text { Gusman e Alcon (2009); Dias } \\
\text { (2009) }\end{array}$ \\
\hline $\begin{array}{l}\text { Pesquisas que sugerem a } \\
\text { análise contrastiva para o } \\
\text { ensino de LE }\end{array}$ & $\begin{array}{l}\text { Tagnin (2004); Schmied (2004); } \\
\text { Dias (2009); Calvo Capilla } \\
\text { e Ridd (2009); Bohunovsky } \\
\text { (2009); Rocha (2011a; 2001b); } \\
\text { Götz (2011); Gysel (2011) }\end{array}$ \\
\hline $\begin{array}{l}\text { Pesquisas que defendem o } \\
\text { uso da LM, no ensino de LE, } \\
\text { especialmente nos níveis inicais }\end{array}$ & $\begin{array}{l}\text { Pedroso (2006); Bohunovsky } \\
\text { (2009); Ferroni (2011) }\end{array}$ \\
\hline $\begin{array}{l}\text { Pesquisas que sugerem o uso de } \\
\text { textos audiovisuais e tradução } \\
\text { no ensino de LE }\end{array}$ & $\begin{array}{l}\text { Vigata e Barbosa (2009); } \\
\text { Esqueda; Oliveira; Jesus (2011); } \\
\text { Alves (2012) }\end{array}$ \\
\hline $\begin{array}{l}\text { Pesquisas que asseveram que a } \\
\text { tradução facilita a compreensão } \\
\text { intercultural no ensino de LE }\end{array}$ & $\begin{array}{l}\text { Guzman e Alcon (2009); } \\
\text { Bohunovsky (2009); Rocha } \\
\text { (2011a); Santoro (2011); Gysel } \\
\text { (2011) }\end{array}$ \\
\hline $\begin{array}{l}\text { Pesquisas que sugerem o uso da } \\
\text { tradução no ensino de LE }\end{array}$ & $\begin{array}{l}\text { Frisene (2009); Branco (2009; } \\
\text { 2011); Romanelli (2009); e todas } \\
\text { as pesquisas supracitadas }\end{array}$ \\
\hline
\end{tabular}

Quadro 2: Pontos de convergência entre as pesquisas da agenda

A contribuição de cada pesquisa acima é, sem dúvida, bastante significativa para o trabalho com tradução em sala de aula de LE. Tratam-se de estudos que destacam várias possibilidades de inserção da tradução no ensino de LE, partindo de um arcabouço teórico e, em muitos deles, propondo atividades práticas. As questões discutidas nessa agenda servem como pilares ao uso da tradução em sala de aula de LE e fomentam novas investigações a respeito do assunto, bem como a proposição e uso de novas práticas em sala de aula. 


\section{Considerações Finais}

O número de artigos publicados sobre tradução e ensino de LE nas revistas que investigamos é ainda muito pequeno. Como pôde ser visto, a pesquisa nesse âmbito está fragmentada, o que poderia ser entendido como um aspecto positivo, uma vez que isso poderia representar uma diversidade no campo de estudo, não fosse o pequeno volume de publicações. Ao passo que divergem em temas, notamos que essas pesquisas convergem em muitos pressupostos como, por exemplo, o uso da tradução pedagógica, a importância do cotejamento de línguas, o papel da LM no aprendizado de uma LE, o uso da tradução também como estratégia de redução do filtro afetivo.

Pôde-se perceber, ainda, que os trabalhos, via de regra, fazem um breve histórico da tradução no ensino de LE, apresentando o MGT como a principal abordagem a influenciar a criação de um estereótipo para o uso da tradução nesse âmbito. Esse histórico é realmente necessário, porque nos ajuda a entender que os métodos estão relacionados com as demandas e com as crenças de cada época e lugar. Os autores das pesquisas dessa agenda sinalizam o retorno da tradução à sala de aula de LE, utilizada de diversas formas e não mais como método principal de ensino, mas como uma ferramenta complementar que pode preencher as carências encontradas por professores e alunos.

O presente estudo descreve o estado da arte em pesquisas sobre "tradução e ensino de LE", contribuindo para uma reflexão sobre o tema a partir dos dados coletados, expostos e discutidos; propondo, também, a definição de uma agenda planejada e mais orgânica para a próxima década. Observe-se, todavia, que, nesse estudo, o recorte de tempo e periódicos tem suas limitações, fazendo-se necessários outros estudos que contemplem outras revistas, trabalhos de conclusão de cursos (dissertações, teses), livros, ou mesmo um período diverso do que foi investigado aqui. 


\section{Notas}

1. Usa-se, aqui, a expressão "língua estrangeira" (LE) como um termo guardachuva, ou seja, sempre que se estiver falando de línguas que não são nativas, abarcando assim, também, a noção de segunda língua (L2).

2. Todas as revistas são conceito Qualis (CAPES) B3 a A1. Optamos por estabelecer esse critério de qualidade para que ficasse clara a credibilidade (dada pelo conceito Qualis-CAPES) de cada revista consultada. A inclusão das revistas conceito B3 é devido ao fato de buscar-se contemplar, também, revistas que versam especificamente sobre tradução, duas delas enquadram-se nesse conceito de acordo com a última avaliação trienal.

3. (...) "a text collection that is the basis for linguistic analysis and, in more restricted terms nowadays, as computer-readable (i.e. in electronic form) and maximally representative.

4. Substituiu-se "LNM" do texto original por "LE" na citação. Pedroso opta por usar a terminologia LNM (línguas não-maternas); como exposto no texto introdutório desta pesquisa, optamos por LE.

5. De acordo com a hipótese do filtro afetivo discutida por Krashen (2009) fatores como ansiedade, alunos "na defensiva" interferem de forma negativa na aquisição de uma LE. Para diminuir o filtro afetivo deve-se, assim, promover um ambiente de aprendizado onde esses fatores são minimizados. Para uma leitura mais aprofundada, cf Krashen (2009) disponível em http://www.sdkrashen.com/ content/books/principles_and_practice.pdf

6. Documentos disponíveis para consulta em: http://portal.mec.gov.br 


\section{Referências}

ALVES, S. F. A adaptação na sala de aula: relato da adaptação do conto "Kew Gardens", de Virginia Woolf, para o curta-metragem Intervalo e suas implicações na prática de tradução. Traduzires. Brasília, v. 1, n. 2, p. 102-116, 2012. Disponível em: < http://periodicos.unb.br/index.php/traduzires/index $>$. Acesso em: 16 nov. 2014.

BAKHTIN, M. Marxismo e filosofia da linguagem. São Paulo: Hucitec, 2006.

BOHUNOVSKY, R. O ensino de línguas estrangeiras no Brasil e a "compreensão do estrangeiro": o papel da tradução. Horizontes de Linguística Aplicada. Brasília, v. 8, n. 2, p. 170-184, 2009. Disponível em: < http://periodicos.unb.br/index. php/horizontesla/index > . Acesso em: 16 nov. 2014.

BRANCO, S. Teorias da tradução e o ensino de língua estrangeira. Horizontes de Linguística Aplicada. Brasília, v. 8, n. 2, p. 185-199, 2009. Disponível em: < http://periodicos.unb.br/index.php/horizontesla/index > . Acesso em: 16 nov. 2014.

. As faces e funções da tradução em sala de aula de língua estrangeira. Cadernos de Tradução. Florianópolis, v. 1, n. 27, p. 161-177, 2011. Disponível em: $<$ https://periodicos.ufsc.br/index.php/traducao/index $>$. Acesso em: 16 nov. 2014.

CALVO CAPILLA, M. C.; RIDD, M. A tradução como atividade contrastiva e de conscientização na aprendizagem de línguas próximas. Horizontes de Linguística Aplicada. Brasília, v. 8, n. 2, p. 150-169, 2009. Disponível em: $<$ http:// periodicos.unb.br/index.php/horizontesla/index > . Acesso em: 16 nov. 2014.

DIAS, F. G. R. O processo de elaboração de um glossário bilíngue de colocações da área médica: contribuições para tradutores e professores de língua inglesa. Horizontes de Linguística Aplicada. Brasília, v. 8, n. 2, p. 153-170, 2009. Disponível em: $<$ http://periodicos.unb.br/index.php/horizontesla/index $>$. Acesso em: 16 nov. 2014. 
ESQUEDA, M. D.; OLIVEIRA, R.; JESUS, S. "A Grande Família - O Filme" e "The Big Family - The Film": a tradução no ensino comunicativo de línguas. TradTerm. São Paulo, v. 18, p. 265-296, 2011. Disponível em:< http://myrtus. uspnet.usp.br/tradterm/site/ > . Acesso em: 16 nov. 2014.

FERRONI, R. O papel da língua materna na sala de língua. In-Traduções. Florianópolis, v. 3, n. 5, p. 82-94, 2011. Disponível em:<http://incubadora. periodicos.ufsc.br/index.php/intraducoes/index > . Acesso em: 16 nov. 2014.

FRISENE, P. D. R. Crenças de alunos de um curso técnico sobre o papel da tradução no ensino instrumental de línguas. Horizontes de Linguística Aplicada. Brasília, v. 8, n. 2, p. 27-46, 2009. Disponível em:< http://periodicos.unb.br/ index.php/horizontesla/index $>$. Acesso em: 16 nov. 2014.

GAMBYER, Y. Multimodality and Audiovisual Translation. MuTra Audiovisual Translation Scenarios: Conference Proceedings. Copenhagen, $\mathrm{p}$ 1-9, 2006. Disponível em: $<$ http://euroconferences.info/proceedings/2006 Proceedings/2006_Gambier_Yves.pdf. Acesso em: 29 nov. 2014.

GÖTZ, H. B. Tradução de frases: uma tentativa deliberada de fazer alunos deixarem de falar inglês em português!. Cadernos de Tradução. Florianópolis, v. 1, n. 27, p. 261-279, 2011. Disponível em:<https://periodicos.ufsc.br/index. php/traducao/index > . Acesso em: 16 nov. 2014.

GUZMAN, J. R.; ALCÓN, E. Translation and language learning: AlfraCovalt as a tool for raising learners' pragmalinguistic and sociopragmatic awareness of the speech act of requesting. Horizontes de Linguística Aplicada. Brasília, v. 8, n. 2, p. 238-254, 2009. Disponível em:< http://periodicos.unb.br/index.php/ horizontesla/index >. Acesso em: 16 nov. 2014.

GYSEL, E. V. O enriquecimento cultural através de atividades de tradução em aulas de língua estrangeira. In-Traduções. Florianópolis, v. 3, n. 5, p. 3949, 2011. Disponível em: $<$ http://incubadora.periodicos.ufsc.br/index.php/ intraducoes/index > . Acesso em: 16 nov. 2014.

KRASHEN, D. S. Principles and Practice in Second Language Acquisition. Stephen D Krashen, 2009. Disponível em:< http://www.sdkrashen.com/>. Acesso em: $21 \mathrm{dez} .2014$. 
MINISTÉRIO DA EDUCAÇÃO. Orientações Curriculares para o Ensino Médio - Linguagens, códigos e suas tecnologias. - Brasília: Ministério da Educação, Secretaria de Educação Básica, 2006. 239 p.

. Parâmetros Curriculares Nacionais 2000 - Ensino Médio (Parte I -

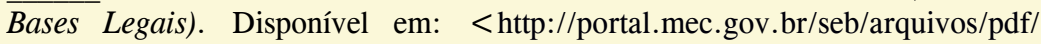
blegais.pdf $>$. Acesso em 04 de fev. de 2013.

. Parâmetros Curriculares Nacionais 2000 - Ensino Médio (Parte II Linguagens, Códigos e suas Tecnologias). Disponível em: http://portal.mec.gov. br/seb/arquivos/pdf/14_24.pdf Acesso em: 02 de jan. 2013.

. PCN+ - Orientações Educacionais Complementares aos Parâmetros Curriculares Nacionais. Disponível em: http://portal.mec.gov.br/seb/arquivos/ pdf/linguagens02.pdf. Acesso em 15 de fev. 2013.

PEDROSO, S. F. Leitura, literatura e tradução: a necessidade de adequações no ensino de línguas não-maternas. Revista Brasileira de Linguística Aplicada. Belo Horizonte, v. 6, n. 1, p. 11-25, 2006. Disponível em: < http://www.scielo. $\mathrm{br} /$ scielo.php? script $=$ sci_serial\&pid $=1984-6398 \& \operatorname{lng}=\mathrm{pt} \& \mathrm{nrm}=\mathrm{iso}>$. Acesso em: 16 nov. 2014.

ROCHA, N. F. F. Translation as a teaching tool to bridge L1 and L2 for adult learners at elementary levels. Cadernos de Tradução. Florianópolis, v. 1, n. 27, p. 179-202, 2011a. Disponível em:<https://periodicos.ufsc.br/index.php/ traducao/index >. Acesso em: 16 nov. 2014.

ROCHA, N. F. F. Tradução literal e aprendizagem de línguas estrangeiras: uma estratégia para memorização. In-Traduções. Florianópolis, v. 3, n. 5, p. 82-94, 2011b. Disponível em: < http://incubadora.periodicos.ufsc.br/index.php/ intraducoes/index $>$. Acesso em: 16 nov. 2014a.

ROMANELLI, S. O uso da tradução no ensino-aprendizagem das línguas estrangeiras. Horizontes de Linguística Aplicada. Brasília, v. 8, n. 2, p. 200219, 2009. Disponível em:< http://periodicos.unb.br/index.php/horizontesla/ index > . Acesso em: 16 nov. 2014. 
SANTORO, E. Tradução e ensino de línguas estrangeiras: confluências. Cadernos de Tradução. Florianópolis, v. 1, n. 27, p. 147-160, 2011. Disponível em: $<$ https://periodicos.ufsc.br/index.php/traducao/index $>$. Acesso em: 16 nov. 2014.

SCHMIED, J. Translation corpora in contrastive research, translation and language learning. TradTerm. São Paulo, v. 10, p. 83-115, 2004. Disponível em: < http://myrtus. uspnet.usp.br/tradterm/site/ > . Acesso em: 16 nov. 2014.

SISTEMA INTEGRADO CAPES. WEBQUALIS. Disponível em: < http://qualis. capes.gov.br/webqualis/publico/pesquisaPublicaClassificacao.seam?conversation Propagation $=$ begin $>$. Acesso em 17 nov. 2014.

TAGNIN, S. E. O. Um corpus multilíngüe para ensino e Tradução - o comet: Da construção à exploração. TradTerm. São Paulo, v. 10, p. 117-141, 2004. Disponível em: < http://myrtus.uspnet.usp.br/tradterm/site/ > Acesso em: 16 nov. 2014.

VIGATA, H. S. Quem arrancou essa planta do meu jardim? Argumentos a favor do uso de legendas interlinguais no ensino de língua estrangeira. Horizontes de Linguística Aplicada. Brasília, v. 8, n. 2, p. 220-237, 2009. Disponível em: < http://periodicos.unb.br/index.php/horizontesla/index $>$. Acesso em: 16 nov. 2014.

Recebido em: 15/07/2015 Aceito em: 01/09/2015 